\title{
AGRICULTURE CROP SIMULATION MODELS USING COMPUTATIONAL INTELLIGENCE
}

\author{
P. K. Kosamkar \\ School of CSE, MIT WPU, Pune, India \\ Dr. V. Y. Kulkarni \\ School of CSE, MIT WPU, Pune, India
}

\begin{abstract}
Variation in the climatic conditions is the major hurdle in the Agriculture sector to attain high crop yield. The Crop simulation models portray the stage-wise growth of crop with the respective environment condition. The crop simulation models help the farmer to make better decisions for improving the crop yield. Artificial Intelligence, Data mining and Computational Intelligent are becoming more prominent in the agriculture field for decision making because of emerging technology such as GIS, Satellite data and remote sensing data in agriculture. This paper reviews information on crop simulation models using computational intelligence and their application. It also reviews the different types of crop simulation models and their limitation in Agriculture. It also discusses the different crop simulation models in details. Considering the emerging technology in the agriculture field we discussed the future trends of crop simulation models.
\end{abstract}

Key words: Agriculture, Crop Simulation Model, Crop Yield, Climatic Attribute, Computational Intelligence.

Cite this Article: P.K. Kosamkar, Dr. V.Y. Kulkarni, Agriculture Crop Simulation Models Using Computational Intelligence, International Journal of Computer Engineering and Technology 10(3), 2019, pp. 134-140.

$\mathrm{http}: / /$ iaeme.com/Home/issue/IJCET?Volume $=10 \&$ Issue $=3$

\section{INTRODUCTION}

Agriculture is vulnerable to global weather and climatic changes. It needs continuous monitoring to improve crop yield. Crop Simulation Model (CSM) is a valuable tool which aims to identify the influence of environment on crop growth and development. For attaining the sustainable agriculture analysis of climate change around the globe in necessary to support the farmers, policy designer. Crop is described as "an aggregation of individual plant species grown in a unit area for economic purpose". The definition of Crop Growth is "an Irreversible increase in size and volume and is the consequence of differentiation and distribution occurring in the plant". Simulation is described as "reproducing the essence of a system without reproducing the system itself. In simulation the essential characteristics of the system 
are reproduced in a model, which is then studied in an abbreviated time scale" [1]. Following Fig 1 shows the crop modelling which require input data as soil, climate, plant and management which is used by crop simulation model for predicting the crop yield.

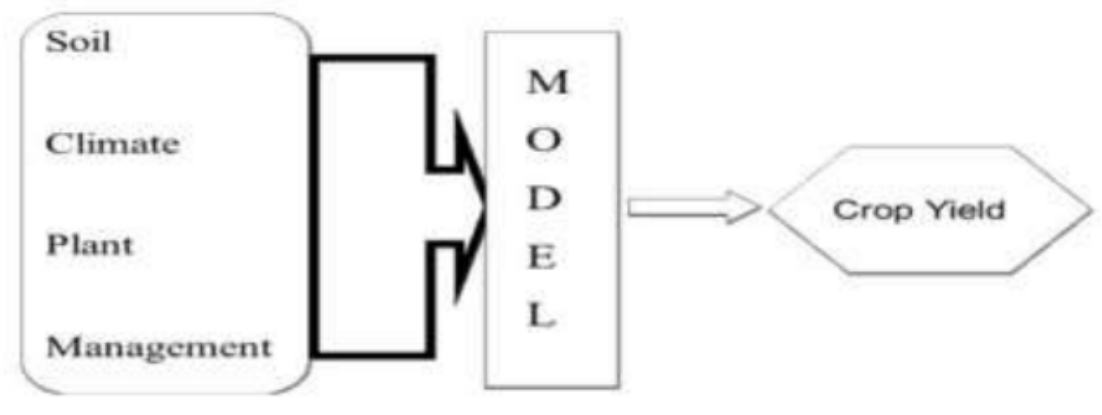

Figure 1. Crop Modelling [26]

Patricia Oteng-Darko et al. mentioned that in crop simulation model the present information of the plant growth, crop physiology, meteorology data of agriculture and soil information is club in consistent, quantative and process-oriented manner [20]. The current development in crop simulation models are based on experimental insight that evaluate the effect of weather, agronomic, hydrologic and soil attribute on yield of the crop.

The paper is organized into following sections. Section I gives the introductory part and importance of the crop simulation models. Section II gives the different types of crop simulation models and how computational intelligence is used in crop simulation models. Section III includes the literature survey of crop simulation models. Section IV mentioned the application area of crop simulation models in agriculture. Section V discusses the limitation of crop simulation models finally Section VI gives the future trends and concludes the paper.

\section{TYPES OF CROP SIMULATION MODELS}

Crop model is nothing but a study of crop growth to find their response to weather, crop management and soil attribute. The main objective of building the crop simulation model is to estimate the growth stages of crops attained over time. The evaluation of crop growth and yield is generally includes crop supervision like irrigation, fertilization, cultivation and protecting plant from diseases. Crop models are categories as Descriptive, statistical, Deterministic, Stochastic, Dynamic and Explanatory types.

Depending upon the aim of the model following are the different classes of crop simulation models,

- Decision Support System for Agrotechnology Transfer (DSSAT) Models [23, 24]: It is a software application which has crop simulation model for 42 different crops (Version 4.7). The input data to this software is daily weather data, soil surface and profile information, and detailed crop management with output as experimental data so that farmers can compare the predicted and actual output. With the help of DSSAT farmers can avail the information on crops and new farm practices to achieve the high crop yield [23, 24].

- Elementary Crop Growth Simulator (ELCROS) Model: The "School of de wit" model attempted to model photosynthetic rates of crop canopies. The output of this model is used for estimating the food production and to provide the indication for crop management and breeding. An Elementary Crop growth Simulator is extension of this model. This model included the static photosynthesis model and crop respiration was taken as a fixed fraction per day of the biomass, plus an amount proportional to the growth rate [1].

- Crop Estimation through Resource and Environment Synthesis (CERES): This model require the input data of weather i.e. minimum and maximum air temperature, longitude, and latitude 
etc. data of soil i.e. soil water content soil texture etc. and data of management practices i.e. sowing dates, irrigation date etc. the model takes the input data mentioned above and predict the different options of management practices for crop yield estimatation. It also forecast the crop status during growing stages. There are different CERES model available for crops like CERES- wheat model, CERES -Rice model.

- WOFOST Model: This model is designed by WOrld FOod STudies in Wageningen (Netherlands). This model require the rain, temp, wind speed, air humidity, soil moisture content, wilting point and management practices as a input. The model analyzes the consequences of weather change, different sowing approaches and crop yield variation for different types of soil. It also use for prediction of the crop yield.

- Environmental Policy Integrated Climate (EPIC) Model: The model was designed for estimating the productivity of soil caused by soil erosion. This model forecast the impact of different management strategies on soil, water, nutrient and pesticide on soil loss, quality of water and yield for area with same types of soil and management [25].

\subsection{Computational intelligence in crop simulation models}

Computational Intelligence (CI) is a heuristic based algorithm that demonstrates emergent adaptive or intelligent behavior used for solving complex optimization problems, adaptive learning, and knowledge acquisition. The growth of computational intelligence in recent years has increased the use of these techniques in different domain of engineering disciplines [2]. The prediction models have used different feature selection methods (FSMs) to capture important attributes, but the issues was the future values of these attributes were not available. To overcome this issues the authors have incorporates an "Autoregressive Integrated Moving Average (ARIMA)" as a feature selection method for computational intelligence (CI) to forecast the rice, wheat and corn rates. Their result shows that this proposed approach attains high prediction performance for food prices [3]. Authors have used the soft computing technique of fuzzy cognitive maps (FCM) for yield prediction of cotton crop production. They have evaluated 360 cases using this methodology during six subsequent years for 5 ha Cotton field [21]. The paper, "Neuro-Fuzzy Modeling for Crop Yield Prediction", used the Adaptive Neuro-Fuzzy Inference System (ANFIS) for forecasting wheat yield using remote sensing and other data. They got acceptable result for wheat yield prediction for the region [22]. The Computational intelligence in crop simulation model will help for optimizing the different type's crop modelling, irrigation and crop prediction etc. $\mathrm{n}$ agriculture sector.

\section{LITRATURE SURVEY}

There are various research papers based on simulation of crop growth and its modelling. These research papers are based on some specific and particular attributes of crop growth, that is, it's dependent on climatic attributes, soil attributes and pest attributes.

On the basis of soil and weather attributes Monteith et al. confirmed that cumulative seasonal light interception for various crop grown with sufficient soil water supply was strongly related to biomass production. They have used the crop simulation model CERES and ELCROS [4]. Further Fei, Qing-Pei and Ripley have used the CERES-Wheat model for forecasting the crop yield in southern Saskatchewan area. For experiment purpose authors have used 25 years of historical data from Saskatoon district. Their result reveled that CERES model was able to simulate crop yield from 1960-1984 years with a correlation coefficient of 0.70 [5]. The CERES-Wheat model was designed with input such as time span of crop growth without disease, water, or pest stress for finding the crop yield. The model was also used to measure the time span of growth cycle of various genetic types of wheat [6]. 
Temperature is one of the important attribute of environment influencing the crop plants growth. How temperature affect on the phenology and yield of crop plant is analyzed by Bishnoi et al. They performed the experiment under field condition through accumulated heat unit system [7]. S. S. Hundal et al. used CERES-Wheat model for forecasting the crop yield for the year 1985 to 1993.Their result revealed the satisfactory prediction of phenology, growth and yield for wheat under 8 crop seasons [8]. Xian Wang et al. used the CERESWheat model for predicting the pre-harvest yield of winter wheat under developing conditions in Beijing. They also mentioned that by considering the other factors like plant disease influence, soil properties spatial variability etc. the prediction and assessment will be improved. They also analyzed the reason for the difference between predicted high yield and actual yield [9]. The comparison of four crop simulation models SPASS, CERES-Wheat, SUCROS and GECROS for growth of spring wheat matured in open-top chamber in various environmental conditions using Expert-N package. They studied the influence of water limitation and elevated atmospheric $\mathrm{CO}_{2}$ concentration on biomass production. Their result shows that SUCROS model gives best simulation result [10]. Parameterization in EPIC model is evaluated using radiation use efficiency and light interception coefficient for cotton in the year 2006 and 2007 in South Texas under various irrigation practices. Their result shows that proper valuation of the model is important for reproducing farm conditions very well in simulating growth and yield of crop [11]. Dirmeyer et al. used the land or soil attribute for General Circulation model (GCM) .They revealed that addition of dormant vegetation during spring and early summer in GCM reduces surface moisture fluxes by removing transpiration from leaves and avoid further depletion of moisture in the root zone of soil [12].

Different parameter of soil i.e. soil type, PH, copper, suphur etc. have used to predict the suitable crop using artificial neural network approach for agriculture crop yield prediction by Dahiker and Rode [13]. Recognition of rice yield and growth in varied climate was done by the use of Decision Support System for Agro Technology Transfer model. For simulation of rice yield daily weather data and soil data was considered. The experiment is conducted to find the yield and growth of two types of rice (At362 and Bg357) grown in Nilwala river basin at Yala season under the global varying climate scenario Representative Concentrate Pathway (RCP) 8.5 [14].

Crop simulation techniques and Early Warning Research are the tools that simultaneously integrate soil, plant and climate factors in determining crop demand for estimating Gain Yield and future needs. The authors have adopted early warning decision support system Anomaly hot Spots of Agricultural Production (ASAP) for furnishing the data for probable crop production anomalies. It's a two step analysis model which categories four agriculture production deficit warning categories. It uses rainfall and vegetation index anomalies for crop production [15]. Authors have designed a data assimilation-crop modeling framework. This model integrates the remotely sensed data of soil moisture and leaf area index with crop model using sequential data assimilation. Their result revealed that the correlation between soil moisture and leaf are index improve the yield [16]. Characterization of maize production environments in the U.S. Corn Belt was done by modifying CERES-Maize simulation model club with Geographic Information Systems. The authors check the usefulness of model to explain Genotype Environment Interactions in commercial hybrids. They also suggested that spatial (Location) and temporal (Year) information will be used for improving the probability of cultivar performance [17]. Historical wheat data and related plantation area, rainfall \& temperature when club with statistic and artificial neural network generate satisfactory prediction of wheat yield. Their result show that Spatial NN model give better result in terms of forecasting yield when compared to temporal Nonlinear Autoregressive Neural Network (NARNN) NARNN and Nonlinear Autoregressive with External Input Neural Network (NARXNN) Model [18]. An artificial neural network (ANN) model was used to predict rice 
potential in Astane region, Northern Iran. Rice Potential production was calculated using AEZ model. Authors have used Mean absolute error (MAE), root mean square error (RMSE) and coefficient of determination (R2) was used to assess the performance of the ANN for rice Yield [19].

\section{APPLICATIONS OF CROP SIMULATION MODELLING}

The researchers have introduced applications of the computational intelligence in agriculture. These applications are,

- Yield Prediction: Prediction of crop yield before harvesting depending upon the environmental condition.

- Crop management optimization: by improving management practices production of crop will improve.

- We can analyze the actual crop yield and predicted crop yield by using these crop simulation models.

- Field specific experimentation: Crop simulation model will reduce the field visit.

- Climate change characterization: by using these models we can find the impact of climate variation on crop growth.

- Policy analysis: It will help policy makers to frame better policies $\mathrm{s}$ by analyzing the result of these crop models.

\subsection{Use of Crop Growth Models}

If farmer know the losses before hand then he will be able to make the decision for different farming activities like crop yield, diseases, growth etc. to reduce the losses. In this scenario crop simulation and early warning research tools play a role; these tools will help the farmer to increase the gain yield. Following are the use of crop growth models,

- Whenever the farmers face the problem of managing their crops on unhealthy soil and climate change [1].

- Whenever the scientists and agro manager need tools and devices that can help them in taking an integrated approach to discover the answer for the complicated environment and crop management [1].

- For framing the policy in agriculture which will help in agrometerology [1].

\section{CONCLUSION AND FUTURE TRENDS}

Crop simulation models for agriculture decision making is becoming more beneficial because of development in technology. Crop simulation models are effective tool for predicting possible impact of climate change, soil attribute, management practices on crop yield and growth. This paper reviews the information on crop growth simulation models using computational intelligence. It reviews the different types of crop simulation models, where we can use the crop models in agriculture and limitation. The crop simulation models used in agrometerology was discussed in details. Considering the emerging technology in agriculture field we discussed the future trends of crop simulation models.

Crop simulation techniques and Early Warning Research are the tools that simultaneously integrate soil, plant and climate factors in determining crop demand for estimating gain yield and future needs. Geographic Information System (GIS), Remote Sensing application will definitely help in crop simulation model for better decision option in Agriculture. Now a day's satellite data is also available which will help in crop simulation model for analysis and 
prediction. Computational Intelligence is an adaptive and heuristic based algorithm which will be useful for solving the complex problem in agriculture like Crop Management Optimization.

\section{REFERENCES}

[1] V. Radha Krishna Murthy, Crop Growth Modeling And Its Applications In Agricultural Meteorology, Satellite Remote Sensing and GIS Applications in Agricultural Meteorology, 2004, 235-261

[2] William Guo, Chih-Cheng Hung, Ross Shepherd, Zhiqiang Ma, Siddhivinayak Kulkarni, Intelligent Techniques for Simulation and Modelling, Hindawi Publishing Corporation, Mathematical Problems in Engineering Volume 2014, Article ID 179457, 3 pages http://dx.doi.org/10.1155/2014/179457

[3] Yuehjen E. Shao and Jun-Ting Dai, Integrated Feature Selection of ARIMA with Computational Intelligence Approaches for Food Crop Price Prediction, Hindawi Complexity, Volume 2018 Article ID 1910520, 17 pages, https://doi.org/10.1155/2018/1910520

[4] John Lennox Monteith C. J. Moss George William Cooke Norman Wingate Pirie George Douglas Hutton Bell, Climate and the efficiency of crop production in Britain, Volume 281, Philosophical Transactions of the Royal Society of London. B, Biological Sciences, 1977 http://doi.org/10.1098/rstb.1977.0140

[5] Qing-Pei Fei, Earle A. Ripley, Saskatchewan Research Council, Simulation of Spring Wheat Yields in the Saskatoon Crop District, 1960 to 1984, Using the CERES Wheat Growth Model, Issue 178 of SRC technical report, ISSN 0715-0407, 1985

[6] Ritchie, J., and Godwin, D., CERES Wheat 2.0, https://nowlin.css.msu.edu/wheat_book/, (accessed 21.04.2019)

[7] Bishnoi OP, Singh S, Niwas R, Effect of temperature on phonological development of wheat crop in different row orientation.(Triticum aestivum L.) Indian J. Agric. Sci. 65:211-214, 1995

[8] Hundal, S. S. and Prabhjyot, K. Application of the ceres-Wheat model to yield predictions in the irrigated plains of the Indian Punjab. Journal of Agriculture Science, 129. 1997, 13-18.

[9] Wang X., Zhao C., Li C., Liu L., Huang W., Wang P., Use of Ceres-Wheat Model for Wheat Yield Forecast in Beijing, In: Li D., Zhao C. (eds) Computer and Computing Technologies in Agriculture II, Volume 1. CCTA 2008. IFIP Advances in Information and Communication Technology, volume 293. Springer, Boston, MA, 2009

[10] Christian Biernath, Sebastian Gayler, Sebastian Bittner, Christian Klein, Petra Högy, Andreas Fangmeier, Eckart Priesack, Evaluating the ability of four crop models to predict different environmental impacts on spring wheat grown in open-top chambers, European Journal of Agronomy, Volume 35, Issue 2,2011, 71-82.

[12] Ko Jonghan, Piccinni Giovanni, Steglich Evelyn, Parameterization of EPIC crop model for simulation of cotton growth in South Texas, Agricultural Water Management, Elsevier ,Volume 96, Issue 9,2009, 1323-1331.

[13] Paul A. Dirmeyer, Vegetation Stress as a feedback Mechanism in Midlatitude Drought, Journal of Climate, Volume 7,1994,1463-1483.

[14] Miss. Snehal S. Dahikar, Dr. Sandeep V. Rode, Agricultural Crop Yield Prediction Using Artificial Neural Network Approach, International Journal Of Innovative Research In 
Electrical, Electronics, Instrumentation And Control Engineering Volume 2, Issue 1, 2014, 683- 686.

[15] M.P.N.M. Dias, C.M. Navaratne, K.D.N. Weerasinghe, R.H.A.N. Hettiarachchi, Application of DSSAT crop simulation model to identify the changes of rice growth and yield in Nilwala river basin for mid-centuries under changing climatic conditions ,International Conference of Sabaragamuwa, University of Sri Lanka (ICSUSL 2015),2016, 159-163 doi: 10.1016/j.profoo.2016.02.039 ,Elsevier.

[16] Felix Rembold, Michele Meroni, Ferdinando Urbano, Gabor Csak, Hervé Kerdiles, Ana Perez-Hoyos, Guido Lemoine, Olivier Leo, Thierry Negre, ASAP: A new global early warning system to detect anomaly hot spots of agricultural production for food security analysis, Journal of Agriculture Systems, 2019, 247-257, https://doi.org/10.1016/j.agsy.2018.07.002, Elsevier

[17] Amor V.M. Ines, Narendra N. Das, James W. Hansen, Eni G. Njoku, Assimilation of remotely sensed soil moisture and vegetation with a crop simulation model for maize yield prediction, Journal of Remote Sensing of Environment, 2013, 149-164, http://dx.doi.org/10.1016/j.rse.2013.07.018,Elsevier.

[18] Carlos M. Lo "ffler, Jun Wei, Tim Fast, Joe Gogerty, Steve Langton, Marlin Bergman, Bob Merrill, and Mark Cooper, Classification of Maize Environments Using Crop Simulation and Geographic Information Systems Published in Crop Sci. 45:1708-1716, Crop Breeding, Genetics \& Cytology ,doi:10.2135/cropsci2004.0370 (C) Crop Science Society of America ,2005.

[19] William W.Guo, and Heru Xue, Crop Yield Forecasting Using Artificial Neural Networks: A Comparison between Spatial and Temporal Models ,Hindawi Publishing Corporation Mathematical Problems in Engineering Volume 2014, Article ID 857865, 7 pages http://dx.doi.org/10.1155/2014/857865

[20] Nafiseh Yaghmaeian Mahabadi ,Use of the Intelligent Models to Predict the Rice Potential Production, International Academic Journal of Innovative Research Volume 2, 2015, 20-31.

[21] Patricia Oteng-Darko, S. Yeboah, S. N. T. Addy, S. Amponsah and E. Owusu Danquah, Crop modeling: A tool for agricultural research -A review ,E3 Journal of Agricultural Research and Development Volume 1,2013,001-006.

[22] E.I.Papageorgiou A.T.Markinos, T.A.Gemtos,"Fuzzy cognitive map based approach for predicting yield in cotton crop production as a basis for decision support system in precision agriculture application", Applied Soft Computing Volume 11, Issue 4, June 2011, 3643-3657, Elsevier ,https://doi.org/10.1016/j.asoc.2011.01.036

[23] D. Stathakisa, I. Savina, T. Nègrea,"Neuro-Fuzzy Modeling For Crop Yield Prediction", Ec-Jrc/Mars-Food, TP266, 21020 (VA), Italy.

[24] Hoogenboom, G., C.H. Porter, V. Shelia, K.J. Boote, U. Singh, J.W. White, L.A. Hunt, R. Ogoshi, J.I. Lizaso, J. Koo, S. Asseng, A. Singels, L.P. Moreno, and J.W. Jones. 2019. Decision Support System for Agrotechnology Transfer (DSSAT) Version 4.7.5 (https://DSSAT.net). DSSAT Foundation, Gainesville, Florida, USA.

[25] Jones, J.W., G. Hoogenboom, C.H. Porter, K.J. Boote, W.D. Batchelor, L.A. Hunt, P.W. Wilkens, U. Singh, A.J. Gijsman, and J.T. Ritchie. 2003. DSSAT Cropping System Model. European Journal of Agronomy 18:235-265.

[26] https://blackland.tamu.edu/models/epic/

[27] B. Chakrabarti, Crop Simulation Model 